\title{
Innovative learning approaches in an established medical school: the experience at JUST in Jordan
}

I. Beni Hani, ${ }^{1}$ K. Al Saudi ${ }^{2}$ and A. Alkafajei ${ }^{3}$

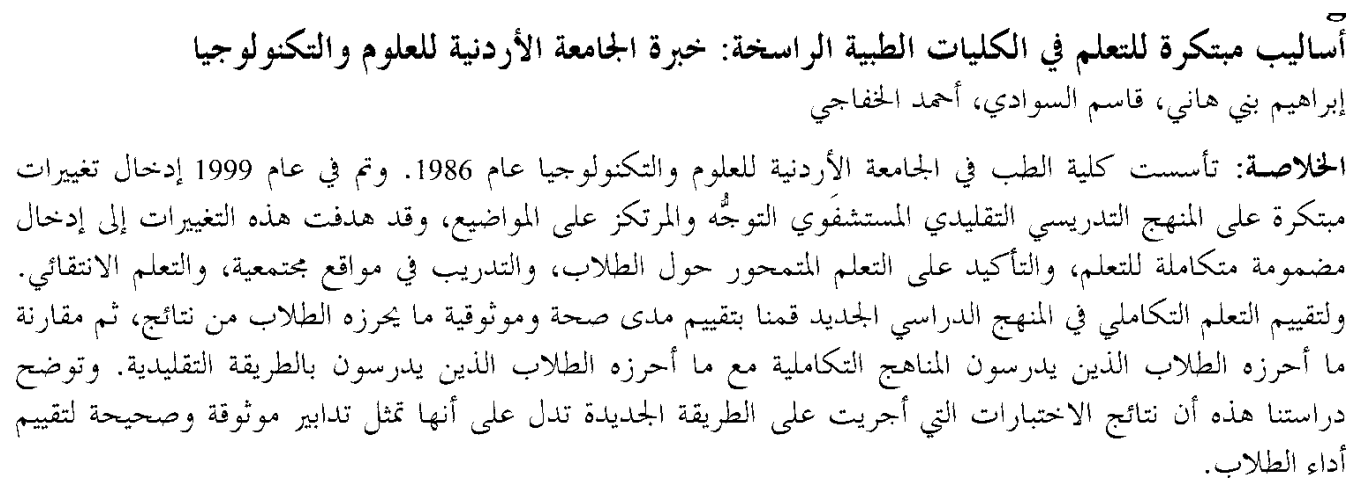

ABSTRACT The Faculty of Medicine at Jordan University of Science and Technology was established in 1986. Innovative changes were introduced to the traditional subject-based, hospital-oriented curriculum in 1999, the objectives of which were to integrate student learning, emphasize student-centred learning, develop training in a community setting, and introduce elective learning packages. To evaluate the integrated learning in the new curriculum, we assessed the validity and reliability of students' scores. The scores for the integrated 'modules' were compared with those in general subjects studied in the traditional way. Our study showed that results of tests taken on the new 'modules' are both valid and reliable measures of students' performance.

Approches didactiques novatrices dans une école de médicine bien établie : l'expérience de I'Université jordanienne des sciences et de la technologie

RESUME La Faculté de médecine de l'Université jordanienne des sciences et de la technologie a été créée en 1986. Des changements novateurs ont été introduits en 1999 dans le programme traditionnel d'études par matières à orientation hospitalière ; ces changements avaient pour objectifs d'intégrer l'apprentissage des étudiants, de faire une large place à l'apprentissage centré sur l'étudiant, de développer la formation au sein de la communauté, et d'introduire des modules d'apprentissage optionnels. Pour évaluer l'apprentissage intégré dans le nouveau programme, nous avons déterminé la validité et la fiabilité des scores des étudiants. Les scores pour les modules intégrés ont été comparés avec ceux obtenus dans les disciplines générales étudiées de manière traditionnelle. Notre étude montre que les résultats des tests passés sur les nouveaux « modules » sont des mesures valables et fiables de la performance des étudiants.

${ }^{1}$ Faculty of Medicine, Jordan University of Science and Technology, Irbid, Jordan.

${ }^{2}$ Department of Pharmacology; ${ }^{3}$ Department of Public Health, Faculty of Medicine, Jordan University of Science and Technology, Irbid, Jordan.

Received: 01/05/02; accepted: 26/02/03 


\section{Introduction}

\section{The medical school}

The Faculty of Medicine in Jordan University of Science and Technology (JUST) was established in 1986. It was the second faculty of medicine to be opened in Jordan (the first being at the University of Jordan in Amman). The campus also houses the 860-bed teaching hospital, King Abdullah University Hospital. The first group of students graduated in June 1991. Annual student intake increased from around 50 in the early years to about 200 in more recent years. The original 6-year curriculum followed the well-established traditional, discipline-based, hospital-oriented model.

\section{Rationale for innovation}

Global standards of medical education and the evolving needs of the national health system

The curriculum content is a balance between universals such as the basic sciences and clinical skills, and the particular local health priorities as determined by the community context and the national health system, and embracing the socioeconomic, environmental, health and cultural characteristics of both. Education should take full account of this context.

Global changes in medical education, namely the increasing globalization of medicine and the global initiatives to establish international standards for the content, process, and educational outcome of undergraduate medical education programmes, give great consideration to the issue of context [1-3].

The common ground for internationally sound standards in medical education must be the academic quality and clinical development of the student. But without application to context, medical education is incomplete. Context must be attended to by addressing the needs of the national health system, and health personnel training programmes should primarily cater to the needs of the health care services.

\section{Health needs of the community}

The health needs of the community were assessed and an appraisal of the functional components of the health system helped to determine how far these were conducive to meeting those needs. It was evident that the traditional curriculum, which is individual patient-oriented and hospital-based, lacked the desired social orientation of health and disease. Student training was invariably centred around disease from the narrow angle of diagnosis and management.

In designing the new curriculum, the challenges that lie ahead and the tasks medical students have to perform have to be brought to the fore. The recognized importance of health care delivery in the community and the importance of improving training in family medicine should constitute the pillars on which curriculum innovation is built $[4,5]$. It was therefore decided that both the learning objectives and the training setting had to be remodelled.

\section{Fragmentation of learning}

An increased orientation towards the consumer, i.e. the student, and the shift of focus from teacher or trainer to student or trainee was an added mandate that helped in formulating the changes that were needed in the faculty's educational strategy [6].

Another factor was the problems associated with increasing specialization in medicine and the need to view the patient as a whole. The rapid growth of knowledge also fuelled a concern that students were learning less and less about more and more $[7,8]$.

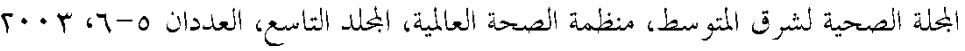


A major shortcoming of traditional teaching is that it fragments the patient into a collection of organs and disease entities. It fails to capture the full psychological and spiritual dimensions of a patient's illness. Physicians can seem only concerned about patients as bearers of pathologies to be eliminated. This is augmented by the artificial division of medical education into components related to the academic departments or disciplines. For example, in a discipline-based curriculum, peptic ulcer is taught separately by each of the following departments: pathology, pharmacology, medicine and surgery.

It was decided that the innovations in the curriculum should introduce the full range and complexity of health, disease, illness and sickness. Students will be trained to be alert to the social conditions in which people live, which are increasingly understood to play an important role in illness and anxiety about illness.

\section{Objectives of the innovation}

The objectives were to integrate student learning, put emphasis on student-centred learning, develop training in a community setting and introduce elective learning packages.

\section{The integrated curriculum}

Horizontal integration between basic and paraclinical disciplines is augmented by the vertical integration with clinical application. The integration of medical sciences with clinical medicine is emphasized even during the early phases of training.

During the first year and a half, the general subjects of basic medical sciences are taught in the traditional subject-based fashion. The next year and a half is devoted to the study of nine body systems called 'modules' - the cardiovascular system, respiratory system, haemopoietic system, digestive system, endocrine system, musculoskeletal system, neuroscience 1 , neuroscience 2 , and the reproductive and urinary system. The remaining 3 years are spent in various clinical disciplines.

\section{Student-centred learning}

The characteristic mode of student assessment in the traditional model is based on testing factual knowledge. In the new curriculum, success is judged by what students learn, rather than what they are taught. The move from an emphasis on the delivery of knowledge by the teacher to student self-learning is reflected in the student-centred approach.

\section{Methods}

In order to evaluate the integrated learning in the new curriculum, we assessed the validity and reliability of students' test scores in the integrated module subjects (both reliability and validity obtained here refer to the results of the tests and not to the tests themselves). The students' test scores in integrated modules were compared with their test scores in general subjects studied in the traditional way.

The study population comprised all second year medical students, 262 in total, for the academic year 2000/2001. They were in the first batch under the new curriculum, and were the first to study the integrated modules during the second semester.

The mean scores of all students in all 4 general subjects studied during the first semester of the second year (pathology, microbiology, pharmacology, and biostatistics) were compared with the mean scores in 3 modules (cardiovascular system, respiratory system, and haemopoietic system) covered during the second semester of the second year. The scores in the 4 
discipline-based general subjects were used as the standard for measuring validity and reliability of scores in the 3 modules.

A student score in any 1 subject, whether it is a general or a module, is made up of scores in 2 mid-term and 1 end of term examinations. The pass score is 50 out of 100 marks. Since these are criterion-referenced examinations, any student with a score of less than 50 is obliged to restudy the subject concerned.

Criterion-related predictive validity was used in this study to see how well test scores achieved in the integrated module subjects could be predicted by the scores obtained in traditionally learned subjects. Criterion-related predictive validity uses a validity coefficient, which is the correlation coefficient, as its index of measurement. The validity coefficient is best determined by the Pearson product-moment technique when large sample size is involved, as in the present study [9].

\section{Results}

The values of central tendency and dispersion of scores in the general and module subjects are shown in Table 1 . It can be seen that there is a wide spread of scores in both the general subjects and the modules as evidenced by the range of values. This variability among scores is necessary for computing validity coefficients.

Table 2 shows the validity coefficients between various subjects expressed as Pearson product-moment correlation coefficient, $r$. All the $r$-values are high enough to indicate a fairly strong positive relationship between the general subjects and the modules, as well as between the module subjects themselves. The larger $r$-values reveal that the characteristics measured in the general subjects and the module subjects are almost the same (e.g. specific knowledge recall and information synthesis). Greater $r$-values usually suggest the stability of the scores is greater, the time span between the examinations has been short and the spread of the scores is large. The calculated validity coefficients in Table 2 also suggest that scores in general subjects (predictor) are actually predictive of the scores in module subjects (criterion).

In Figure 1, the linear regression indicates that high predictor (general subjects) scores tend to correlate with high criterion (modules) scores and that low predictor

\begin{tabular}{lcccc}
\hline $\begin{array}{l}\text { Table 1 Values of central tendency and dispersion of examination } \\
\text { scores in general subjects and in the new modules for } \mathbf{2 6 2} \\
\text { second year students, 2000/2001 }\end{array}$ \\
\hline Subject & $\begin{array}{c}\text { Mean score } \\
\text { (\%) }\end{array}$ & $\boldsymbol{s}$ & Median & Range \\
\hline General (4 subjects) & 67.7 & 12.3 & 66.5 & $38.8-95.8$ \\
Modules (3 subjects) & 65.6 & 12.5 & 65.3 & $35.0-92.7$ \\
Cardiovascular system & 63.8 & 13.7 & 63.0 & $35.0-96.0$ \\
Haemopoietic system & 69.1 & 12.5 & 70.0 & $35.0-94.0$ \\
Respiratory system & 63.6 & 13.2 & 64.0 & $35.0-90.0$
\end{tabular}

$\mathrm{s}=$ standard deviation

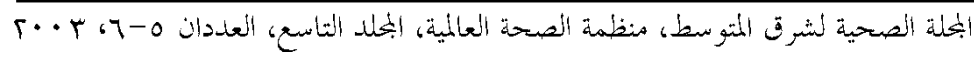




\begin{tabular}{|c|c|c|c|c|}
\hline & General & Modules & $\begin{array}{l}\text { Cardiovascular } \\
\text { system }\end{array}$ & $\begin{array}{c}\text { Haemopoietic } \\
\text { system }\end{array}$ \\
\hline Modules & 0.797 & & & \\
\hline Cardiovascular system & 0.873 & 0.846 & & \\
\hline Haemopoietic system & 0.881 & 0.832 & 0.885 & \\
\hline Respiratory system & 0.776 & 0.956 & 0.781 & 0.765 \\
\hline
\end{tabular}

All $\mathrm{r}$-values are statistically significant, $\mathrm{P}<0.001$.

Using $\mathrm{t}$-test, $\mathrm{t}=\mathrm{r} \sqrt{ }\left[(\mathrm{n}-2) /\left(1-\mathrm{r}^{2}\right)\right]$.

scores tend to correlate with low criterion scores, the coefficients of determination $\left(\mathrm{R}^{2}\right)$ being high in the 4 regression lines.

Table 3 shows that the linear regression lines between scores of the general subjects and those of the modules illustrated in Figure 1 provide good fit to the data (statistically significant).

Again, since these tests are criterionreferenced tests, the reliability of scores obtained in both the general and the module subjects can best be determined by computing the percentage of consistent decisions over any 2 tests. For example, all students obtaining a score of 80 or higher on tests in both general and module subjects are classified as masters in both subjects. All students obtaining a score of less than 80 on both tests are classified as nonmasters on both tests. The remaining students are classified as master on 1 test and nonmaster on the other. If this latter group of reversals is relatively large, the tests are inconsistent in classifying students. Consistency (reliability) is determined as the sum of masters and nonmasters in both tests divided by the total number of students.

Table 4 displays the consistency of examination scores in general subjects with those in the new modules, using different cut-off points for masters. The students' scores reveal higher consistency for the 2 extreme cut-off points, 50 and 80 . The total agreement between scores in general subjects with those in module subjects is in the order of 9 out of 10 students at cut-off points 50 and 80 . However, the majority of those students are classed as masters when the 50 cut-off point is considered, while many of them are classed as nonmasters when 80 is the cut-off point.

\section{Discussion}

The important qualities to consider when evaluating innovative instructional methods are validity and reliability of the results of tests measuring students' achievements in the innovative programme. Testing students' achievements provides information that is used in educational decisions. Evaluation of tests done after the introduction of a new instructional strategy is essential for describing changes in students' performance as well as for judging the desirability of the innovative programme itself.

Measuring the validity of the integrated modules in the present study could best be done by determining the extent to which students achieved the intended objectives 

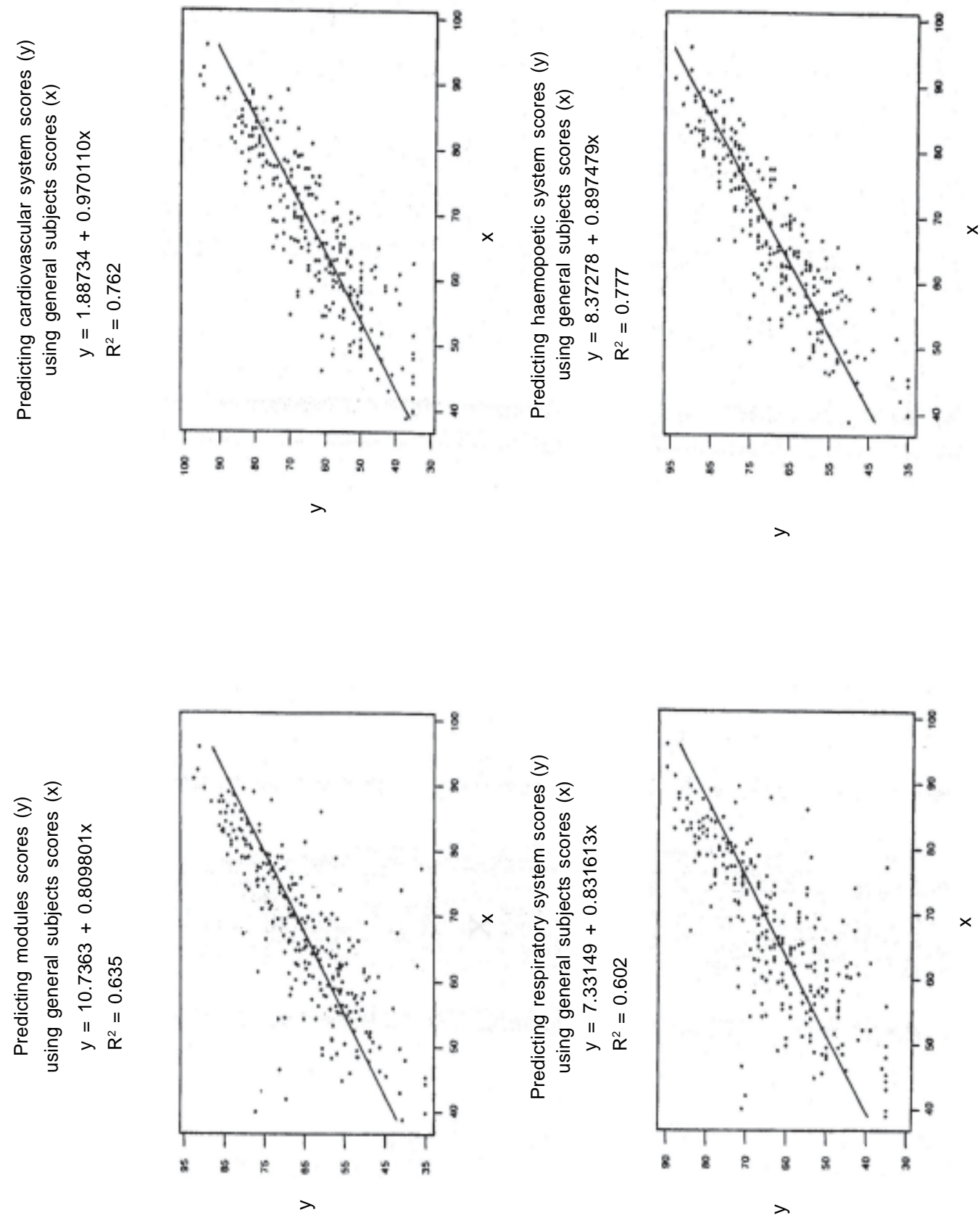

Figure 1 Linear regression of scores on modules on general subjects

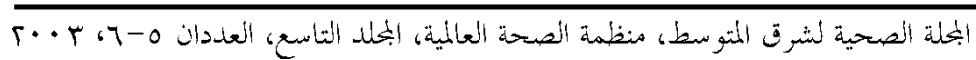




\begin{tabular}{|c|c|c|c|c|c|}
\hline Regression & SS & df & MS & $F$ & $P$ \\
\hline \multicolumn{6}{|l|}{ Modules on general } \\
\hline Linear regression & 25902 & 1 & 25902 & 452.19 & $<0.001$ \\
\hline Residuals & 14893 & 260 & 57 & & \\
\hline \multicolumn{6}{|l|}{$\begin{array}{l}\text { Cardiovascular system } \\
\text { on qeneral }\end{array}$} \\
\hline Linear regression & 37172 & 1 & 37172 & 834.72 & $<0.001$ \\
\hline Residuals & 11578 & 260 & 45 & & \\
\hline \multicolumn{6}{|l|}{$\begin{array}{l}\text { Haemopoietic system } \\
\text { on general }\end{array}$} \\
\hline Linear regression & 31814 & 1 & 31814 & 904.38 & $<0.001$ \\
\hline Residuals & 9146 & 260 & 35 & & \\
\hline \multicolumn{6}{|l|}{$\begin{array}{l}\text { Respiratory system } \\
\text { on general }\end{array}$} \\
\hline Linear regression & 27316 & 1 & 27316 & 392.71 & $<0.001$ \\
\hline Residuals & 18085 & 260 & 70 & & \\
\hline
\end{tabular}

SS = sum of squares.

$d f=$ degrees of freedom

$M S=$ mean square.

of the modules. Validity here refers to the meaningfulness and appropriateness of the interpretations made on test scores rather than on the test instrument itself.

A high degree of correlation was found between the predictor, i.e. general subjects, and the criterion, i.e. module subjects. There was a significant fit for regression lines drawn between the criterion and the predictor. These regression lines support the illustrated high degree of validity of students' performance in the modules.

Table 4 Consistency (\%) of examination scores in general subjects with those in modules using different master cutoff points for 262 second year medical students, 2000/2001

\begin{tabular}{lcccc}
\hline Test subjects & \multicolumn{4}{c}{$\begin{array}{c}\text { Consistency of scores (\%) } \\
\text { Mastery cut-off point }\end{array}$} \\
& $\mathbf{5 0}$ & $\mathbf{6 0}$ & $\mathbf{7 0}$ & $\mathbf{8 0}$ \\
\hline General:modules & 89.3 & 79.0 & 86.2 & 91.2 \\
General:cardiovascular system & 92.0 & 80.2 & 84.4 & 91.6 \\
General:haemopoetic system & 93.9 & 86.2 & 84.7 & 90.8 \\
General:respiratory system & 88.5 & 74.8 & 85.9 & 90.1 \\
\hline
\end{tabular}

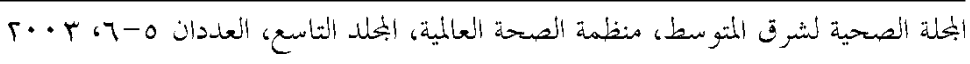


The evaluation of students' test results in the integrated modules of cardiovascular, respiratory, and haemopoietic systems when compared to their performance in subjects taught in the traditional fashion indicates that their performance in these modules has high validity. Examinations done in both modes of teaching were testing almost similar characteristics and the stability of the scores is high.

The results exhibited in Tables 2 and 3 and Figure 1 indicate that students' scores in the integrated modules are accurate (valid) measures of students' performance.

Next to validity, reliability is the most important quality to seek in the evaluation of the innovative instructional method of integrated modules. Again, in interpreting and using reliability information, it is important to remember that reliability estimates refer to the results of the test and not the test itself. It is equally essential to remember that a valid measure is not necessarily reliable and that reliability is strictly a statistical concept.

When criterion-referenced tests are considered, as in this study, it is best to measure reliability by classifying students as masters or nonmasters using an arbitrary cut-off point. The percentage of consistent decisions over two tests provides a simple and effective index of reliability.

The students' performance in these innovative modules has a high degree of reliability. Results obtained from tests on modules are highly consistent with results obtained from traditionally taught general subjects. The results of tests done in the integrated modules give a precise (reliable) measure of students' performance.

The observed high degree of reliability of the innovative modules also provides the consistency that makes validity of these innovations more prominent. Reliability is a necessary condition for validity. The high reliability indices revealed in Table 4 illustrate that the results of the examinations for the new modules are reliable and precise measures of student performance.

In conclusion, we found that the results of students' assessments in the innovative 'modules' are both valid and reliable measures of students' performance.

\section{References}

1. Walton HJ. Medical education worldwide. A global strategy for medical education: partners in reform. Medical education, 1993, 27(5):394-8.

2. Hamilton JD. Establishing standards and measurement methods for medical education. Academic medicine, 1995, 70(7, suppl.):S51-6.

3. International standards in medical education: assessment and accreditation of medical schools' educational programmes. A WFME position paper. Medical education, 1998, 32:549-58.

4. Bligh JG, Harden RM. Bridging the gap between hospital experience and gen- eral practice during vocational training. Medical teacher, 1990, 12:169-73.

5. Toward a global consensus on quality medical education: Serving the needs of populations and individuals. Proceedings of the 1994 World Health Organization/Educational Commission for Foreign Medical Graduates Invitational Consultation. Geneva, Switzerland, October 3-6, 1994. Academic medicine, 1994, 70(7, suppl.):S1-90.

6. Sanson-Fisher RW, Rolfe I. The content of undergraduate health professional courses: a topic largely ignored? Medical teacher, 2000, 22:564-7.

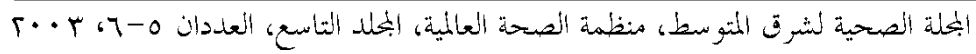


7. Harden RM, Davis MH. The core curriculum with options or special study modules. An extended summary of AMEE Education Guide No. 5. Medical teacher, 1995, 17(2):125-48.

8. Tomorrow's doctors: Recommendations on undergraduate medical education. London, General Medical Council, 1993.
9. Gronlund NE. Measurement and evaluation in teaching, 5th ed. New York, Macmillan, 1985:55-85.

\section{Medical Education in the EMR}

The Regional Office has assigned top priority to human resources policies formulation, planning and management. Human resources policies have been developed in very few countries of the Region. In most cases plans for human resources for health have been worked out in the absence of clear-cut or agreed policies. To meet this deficiency, guidelines for formulation of policies on human resources development, prepared by a working group, are available. Better performance of health personnel has been the most important reason for the emphasis the Regional Office has placed on strengthening and promoting programmes for continuing education as well as programmes on management of human resources.

Source: http://www.emro.who.int/EMROInfo/MedicalEducation.htm

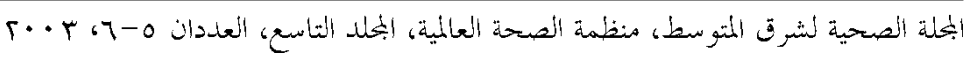

